\title{
Iodine uptake by spinach (Spinacia oleracea L.) plants grown in solution culture: effects of iodine species and solution concentrations
}

\author{
Y.-G. Zhu*, Y.-Z. Huang, Y. Hu, Y.-X. Liu \\ Department of Soil Environmental Sciences, Research Centre for Eco-environmental Sciences, Chinese Academy of Sciences, Beijing 100085, China
}

Received 14 September 2002; accepted 15 October 2002

\begin{abstract}
A hydroponic experiment was carried out to investigate the effects of iodine species and solution concentrations on iodine uptake by spinach (Spinacia oleracea L.). Five iodine concentrations $(0,1,10,50$ and $100 \mu \mathrm{M})$ for iodate $\left(\mathrm{IO}_{3}^{-}\right)$and iodide $\left(\mathrm{I}^{-}\right)$were used. Results show that higher concentrations of $\mathrm{I}^{-}(\geqq 10 \mu \mathrm{M})$ had some detrimental effect on plant growth, while $\mathrm{IO}_{3}^{-}$had little effect on the biomass production of spinach plants. Increases in iodine concentration in the growth solution significantly enhanced I concentrations in plant tissues. The detrimental effect of $\mathrm{I}^{-}$on plant growth was probably due to the excessively high accumulation of I in plant tissues. The solution-tospinach leaf transfer factors $\left(\mathrm{TF}_{\text {leaf }}\right.$, fresh weight basis) for plants treated with iodide were between 14.2 and 20.7 at different solution concentrations of iodide; $\mathrm{TF}_{\text {leaf }}$ for plants treated with iodate decreased gradually from 23.7 to 2.2 with increasing solution concentrations of iodate. The distribution coefficients (DCs) of I between leaves and roots were constantly higher for plants treated with iodate than those treated with iodide. DCs for plants treated with iodide increased with increasing solution concentrations of iodide, while DCs for plants treated with iodate (around 5.5) were similar across the range of solution concentrations of iodate used in this experiment. The implications of iodine accumulation in leafy vegetables in human iodine nutrition are also discussed.
\end{abstract}

(C) 2002 Elsevier Science Ltd. All rights reserved.

Keywords: Iodine; Iodate; Iodide; Spinach; Uptake; Iodine deficiency disorders

\section{Introduction}

Iodine is an essential microelement for human health. Iodine deficiency disorders (IDD) are believed to be one of the commonest preventable human health problems (Welch and Graham, 1999). It has been estimated that there are about 225 million people in the world currently affected by iodine deficiency (goiter), and the population under the risk of iodine deficiency is about 1 billion (World Bank, 1994). While most surveys on IDD are based on visual symptoms of iodine deficiency, i.e. the development of goiter (enlargement of the thyroid), the problem of IDD is likely underestimated considering the occurrence of invisible mental retardation due to iodine deficiency.

Iodine deficiency in China, particularly in western parts of the country, is severe. Although the use of iodized salt has been promoted in China nationwide from the early

\footnotetext{
* Corresponding author. Tel.: +86-10-6293-6940; fax: +86-10-62923563.

E-mail address: ygzhu@mail.rcees.ac.cn (Y.-G. Zhu).
}

1980s, iodine deficiency remains a major health problem in remote provinces in China, such as Xinjiang. In these remote regions, iodine intake by the population is inherently low, because I in soil and drinking water in these regions is generally lower than in coastal regions of the country. Iodine deficiency is further exacerbated by two factors: (1) the ethnic minority people in Xinjiang prefer the rock salt available locally free of charge and (2) Chinese cooking methods with high-temperature oil will result in the volatilization of I (Zhang et al., 2000). The baking of nan (major food for ethnic minorities in Xinjiang) under high temperature (usually around $360{ }^{\circ} \mathrm{C}$ ) is a typical example. A survey in 1999 showed that in Xinjiang, about 23\% of children (aged between 8 and 10) had goiter (Xinjiang Disease Control Centre, 2000). It is therefore suggested that salt fortification with iodine is not enough to eliminate IDD in most remote regions in China, and that multiple approaches for iodine fortification in the food chain should be sought.

In recent years, irrigation of paddy soil with iodized water has been tried in Xinjiang to reduce I deficiency 
(Cao et al., 1994). This practice has been extended in several prefectures in Xinjiang, and has been proved to be a useful approach in reducing iodine deficiency-related health problems locally (Jiang et al., 1997). However, the translocation of I from vegetative organs to grains requires an active phloem transport system for I. A recent study by Mackowiak and Grossl (1999) demonstrated that I taken up by rice plants is largely accumulated in roots, stems and leaves, and the amount of I translocated to rice grains is extremely small, indicating that phloem transport of $I$ is very low (Herrett et al., 1962). Muramatsu et al. (1989) reported that hulled rice contained only $4 \%$ of the I found in the unhulled seed. Based on this information, Mackowiak and Grossl (1999) concluded that even with the highest I concentration in their growth solution (100 $\mu \mathrm{M})$, the I concentration in rice grains was not adequate to meet the recommended daily requirement (RDA) of 150 $\mu \mathrm{g}$ I.

We hypothesize that if the concentration of $\mathrm{I}$ in the edible parts of a crop does not rely on phloem transport, this crop will be more efficient in accumulating I from the growth substrate. The objectives of this study were therefore to investigate whether the leafy vegetable crop spinach (Spinaacia oleracea L.) can efficiently take up I from nutrient solution and accumulate in leaves, and to examine the effects of I species and concentrations on plant growth and I accumulation.

\section{Materials and methods}

\subsection{Plant culture}

The hydroponic experiment was carried out in a growth room with a 14-h light period $\left(260-350 \mu \mathrm{E} \mathrm{m} \mathrm{m}^{-2} \mathrm{~s}^{-1}\right)$. Temperature was set at $28{ }^{\circ} \mathrm{C}$ day and $20{ }^{\circ} \mathrm{C}$ night.

Seeds of spinach (S. oleracea $\mathrm{L}$.) were disinfected in $10 \%$ $\mathrm{H}_{2} \mathrm{O}_{2}$ solution for 10 min followed by thorough washing in

Table 1

Nutrient composition of the solution used in this study

\begin{tabular}{lc}
\hline Salt & Solution concentration \\
\hline Macronutrients $(m M)$ & \\
$\mathrm{KNO}_{3}$ & 4.0 \\
$\mathrm{Ca}\left(\mathrm{NO}_{3}\right)_{2}$ & 4.0 \\
$\mathrm{MgSO}_{4}$ & 1.5 \\
$\mathrm{KH}_{2} \mathrm{PO}_{4}$ & 1.3 \\
$\mathrm{NaCl}$ & 0.1 \\
& \\
Micronutrients $(\mu M)$ & \\
$\mathrm{Fe}-\mathrm{EDTA}$ & 50 \\
$\mathrm{H}_{3} \mathrm{BO}_{3}$ & 10 \\
$\mathrm{ZnSO}_{4}$ & 1.0 \\
$\mathrm{CuSO}_{4}$ & 1.0 \\
$\mathrm{MnSO}_{4}$ & 5.0 \\
$\mathrm{Na}_{2} \mathrm{MoO}_{4}$ & 0.5 \\
$\mathrm{CoSO}_{4}$ & 0.2 \\
\hline
\end{tabular}

Table 2

Biomass (dry weight) production of spinach grown in nutrient solution supplied with different levels and forms of iodine

\begin{tabular}{|c|c|c|c|c|}
\hline \multirow[t]{2}{*}{ I concentration } & \multicolumn{2}{|l|}{ Shoot } & \multicolumn{2}{|l|}{ Root } \\
\hline & Iodate & Iodide & Iodate & Iodide \\
\hline 0 & 1.97 & 1.66 & 0.50 & 0.41 \\
\hline 1 & 1.48 & 2.37 & 0.35 & 0.61 \\
\hline 10 & 1.94 & 1.19 & 0.48 & 0.38 \\
\hline 50 & 1.36 & 0.73 & 0.35 & 0.29 \\
\hline \multirow[t]{2}{*}{100} & 1.87 & 0.35 & 0.47 & 0.15 \\
\hline & \multicolumn{2}{|c|}{ Analysis of variance } & & \\
\hline I form $(F)$ & $P=0.002$ & NS & & \\
\hline I concentration $(\mathrm{C})$ & $P<0.001$ & $P<0.050$ & & \\
\hline $\mathrm{F} \times \mathrm{C}$ & $P<0.001$ & $P<0.001$ & & \\
\hline $\mathrm{LSD}_{0.05}$ & 0.63 & 0.19 & & \\
\hline
\end{tabular}

deionized water. Seeds were then germinated on moist filter paper for 2-3 days. Geminated seeds were sown in moist vermiculite, and were grown for about 10 days (four-leaf stage). After the initial growth period in the seedbed, seedlings were carefully removed from the seedbed, and were thoroughly washed free of any adhering particles under tap water. Seedlings were then transferred to PVC pots $(7.5 \mathrm{~cm}$ in diameter and $15 \mathrm{~cm}$ in height) containing $500 \mathrm{ml}$ nutrient solution with continuous aeration. Modified Long Ashton nutrient solution was used (Table 1). Two iodine species (iodide and iodate) at five concentrations $(0,1,10,50,100$ $\mu \mathrm{M})$ were used, so altogether, there were 10 treatments, and each treatment had four replicates. Plants were allowed to grow for 21 days in the nutrient solution. Nutrient solution was changed twice a week, and solution $\mathrm{pH}$ was adjusted to 6.0 using dilute $\mathrm{HCl}$ or $\mathrm{KOH}$ solutions. At the termination of the experiment, plant roots were washed in deionized water, and blotted dry. Plants were divided into roots and shoots (leaves), and fresh weights were determined immediately after harvest. Plant materials were then oven-dried at $70{ }^{\circ} \mathrm{C}$ for $72 \mathrm{~h}$, and dry weights were determined for all tissues. Tissues were all ground for I analysis.

\subsection{Iodine analysis}

Neutron activation analysis (NAA) was used to analyze I in plant tissues (Shinonaga et al., 2000), and the procedure was described briefly as below. Dried plant samples and reference materials (150-200 mg per sample) were doublesealed in a polyethylene bag for irradiation. Each sample was irradiated for $15 \mathrm{~min}$ in a nuclear reactor developed by the Chinese Institute of Nuclear Science in Beijing. The thermal neutron flux used was $8.0 \times 10^{11} \mathrm{n} \mathrm{cm}^{-2} \mathrm{~s}^{-1}$. In the irradiation facility, samples were shielded in a BN (boron nitride) box.

Gamma ray of ${ }^{128} \mathrm{I}$ analysis was measured by highresolution $\mathrm{Ge}(\mathrm{Li})$ detectors (Ortec, USA) for $10 \mathrm{~min}$ at $442.9 \mathrm{keV}$. Analysis accuracy was measured on the reference material and was between $2 \%$ and $6 \%$. 


\subsection{Data analysis}

I concentrations (IC) in leaves and roots were calculated both on dry weight and fresh weight basis.

Solution-to-leaf transfer factors $\left(\mathrm{TF}_{\text {leaf }}\right)$ were calculated as follows:

$\mathrm{TF}_{\text {leaf }}=\left[\mathrm{IC}_{\text {leaf }}\right]^{\mathrm{fresh}} / \mathrm{IC}_{\text {solution }}$

where $\left[\mathrm{IC}_{\text {leaf }}\right]^{\text {fresh }}$ is leaf I concentration on fresh weight basis and $\mathrm{IC}_{\text {solution }}$ is the corresponding solution I concentration.

I distribution coefficients (DCs) were defined as the ratio of the total I in leaves to that in roots.

All data are subjected to analysis of variance (ANOVA, two-way) performed using Windows-based Genstat (6th edition, NAG, England).

\section{Results}

\subsection{Plant biomass}

Table 2 shows the biomass of both shoots and roots of spinach plants grown with different forms and levels of

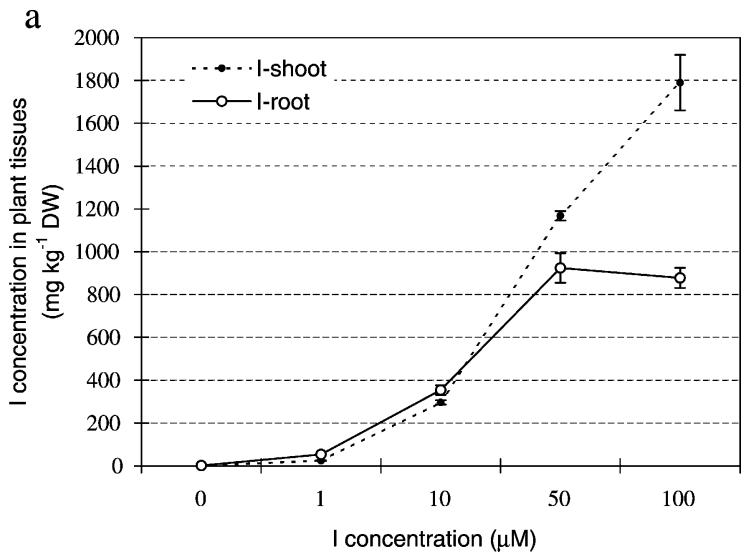

b

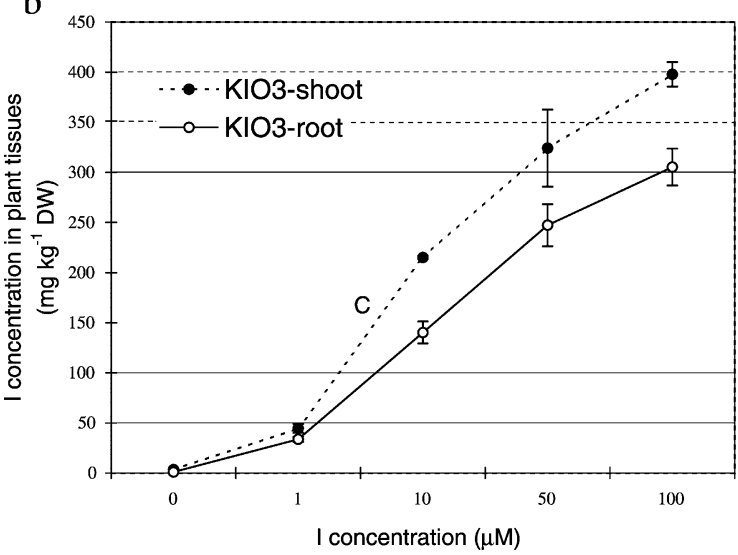

Fig. 1. I concentrations in tissues of spinach plants grown in solution culture treated with different concentrations of iodide (a) and iodate (b). Bars: standard errors.
Table 3

Iodine concentrations in leaves of spinach on fresh weight basis $\left(\mathrm{mg} \mathrm{kg}^{-1}\right)$

\begin{tabular}{lrr}
\hline I concentration $(\mu \mathrm{M})$ & Iodate & Iodide \\
\hline 0 & 0.23 & 0.12 \\
1 & 3.01 & 1.81 \\
10 & 14.72 & 24.67 \\
50 & 24.49 & 119.83 \\
100 & 28.02 & 263.43
\end{tabular}

\begin{tabular}{ll} 
& Analysis of variance \\
\hline I Form $(\mathrm{F})$ & $P<0.001$ \\
I concentration $(\mathrm{C})$ & $P<0.001$ \\
$\mathrm{~F} \times \mathrm{C}$ & $P<0.001$ \\
$\mathrm{LSD}_{0.05}$ & 9.33 \\
\hline
\end{tabular}

iodine in solution culture. The concentration of iodate in the nutrient solution had no significant effect on both shoot and root biomass, although there was some fluctuation at different levels of iodate concentration in the solution. For plants treated with iodide, both shoot and root biomass decreased significantly when the concentration of iodide in the nutrient solution was $10 \mu \mathrm{M}$ or higher. The effects of the interaction between iodine forms and concentrations on plant growth were also significant (Table 2).

\subsection{Iodine uptake}

Increases in iodine concentrations in nutrient solution enhanced I uptake by spinach plants from both forms (Fig. 1). At an I concentration of $1 \mu \mathrm{M}$ in the nutrient solution, I concentration in the leaves of spinach plants treated with iodate was greater than in those treated with iodide $\left(44.5 \pm 4.4\right.$ vs. $\left.24.6 \pm 0.9 \mathrm{mg} \mathrm{kg}^{-1}\right)$; with further increase in I concentration in the nutrient solution, I concentrations in the leaves of spinach plants treated with iodide were much higher than those treated with iodate. The I concentration in leaves of spinach plants treated with $100 \mu \mathrm{M}$ of iodide was

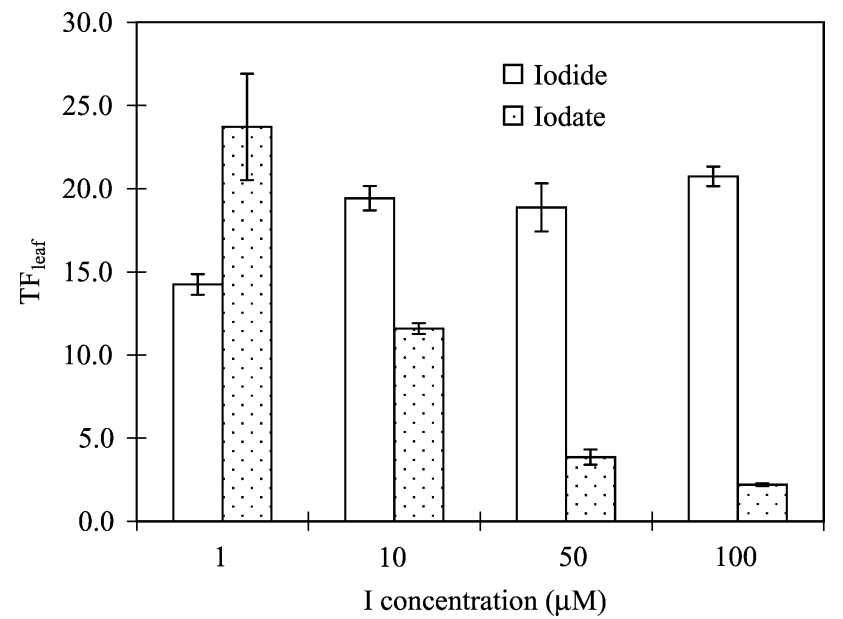

Fig. 2. Solution to leaf transfer factors for spinach plants grown in solution culture treated with different concentrations of iodide and iodate. Bars: standard errors. 


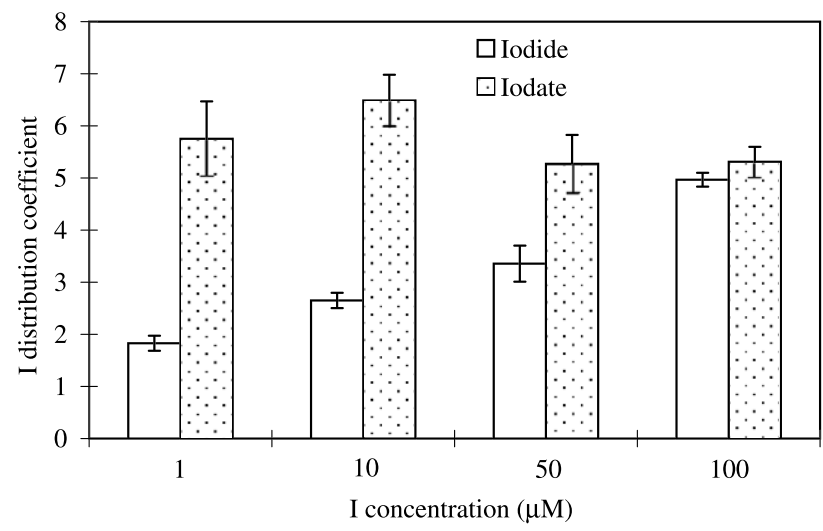

Fig. 3. I distribution coefficients between shoots (leaves) and roots of spinach plants culture treated with different concentrations of iodide and iodate. Bars: standard errors.

$1789.8 \pm 129.5 \mathrm{mg} \mathrm{kg}^{-1}$, which was about fivefold higher than in leaves of plants treated with $100 \mu \mathrm{M}$ of iodate $(397.9 \pm 12.2)$. I concentrations in leaves were generally higher than in roots.

Since spinach is normally consumed as fresh leaves, I concentrations in leaves were also calculated on the fresh weight basis (Table 3). I concentrations on fresh weight basis $\left(\mathrm{IC}_{\mathrm{f}}\right)$ were about tenfold lower than on a dry weight basis. Solution-to-spinach leaf transfer factors $\left(\mathrm{TF}_{\text {leaf }}\right)$ are shown in Fig. 2. For plants treated with iodide, $\mathrm{TF}_{\text {leaf }}$ increased from 14.2 to 19.4 when iodide concentration in the nutrient solution increased from 1 to $10 \mu \mathrm{M}$, and with further increase in iodide concentrations, $\mathrm{TF}_{\text {leaf }}$ remained almost unchanged. For plants treated with iodate, $\mathrm{TF}_{\text {leaf }}$ decreased gradually from 23.7 to 2.2 with increasing solution concentration of iodate.

The distribution coefficients (DCs) of I between leaves and roots are shown in Fig. 3. For plants treated with iodide, the DCs increased significantly with increasing in solution concentration of iodide $(p<0.001)$; while for plants treated with iodate, the DCs were similar across the range of solution concentrations. The DCs for plants treated with iodate were generally higher than in those treated with iodide, particularly at low concentrations of iodine in nutrient solutions, indicating that more I accumulated in leaves when plants were treated with iodate.

\section{Discussion}

Although I is essential for animals, there has been no direct evidence of its essentiality in plant growth. Several studies have shown that a low level of $\mathrm{I}$ in the growth environment $\left(0.02-0.2 \mathrm{mg} \mathrm{kg}^{-1}\right)$ is beneficial to a number of plant species, such as halophytes (Borst Pauwels, 1961). Our results show that $\mathrm{I}$ is not beneficial to the growth of spinach plants, but a high level of iodide $(\geq 10 \mu \mathrm{M})$ is detrimental to yields, which is in agreement with the findings of Mackowiak and Grossl (1999). The detrimental effect of iodide on plant growth is probably due to its excessive accumulation in plant tissues. It has been suggested that iodate is reduced to iodide before its uptake by plant roots (Böszörményi and Cseh, 1960; Whitehead, 1975), therefore the slow uptake rate of iodate is likely to be limited by the reduction process. Under reducing conditions such as paddy soil, I mainly exists as iodide, therefore application of I to paddy soil to increase I accumulation in rice should be considered carefully to avoid any inadvertent yield reduction.

Previous studies have shown that I does not appear to be phloem mobile (Herrett et al., 1962), therefore I accumulation in grains is often very low (e.g. Mackowiak and Grossl, 1999). Mackowiak and Grossl (1999) concluded that supplying dietary I with rice may not be feasible, based on their solution culture study. For leafy vegetables, I accumulation in the edible parts is largely dependent on xylem transport. Therefore, one of the goals of the present study was to demonstrate if I can be effectively accumulated in edible parts (leaves) of spinach, in order to supplement dietary I. Our results (Fig. 2) show that the solution-to-leave transfer factors were generally higher than those reported for rice in solution culture (Mackowiak and Gross1, 1999), and much higher than those reported for wheat grains (average 0.0016) grown in field soils (Shinonaga et al., 2001). Results from this experiment showed that with an iodate concentration of $1 \mu \mathrm{M}$ (about $0.1 \mathrm{mg} \mathrm{kg}^{-1}$ ) in the nutrient solution, I concentration in spinach leaves was around $3 \mathrm{mg}$ $\mathrm{kg}^{-1}$ on a fresh weight basis, which is probably enough to supplement I through dietary intake. Furthermore, our data show that the amount of I accumulated in leaves is much more than in roots (Fig. 3), which is good because normally only leaves are consumed.

Further studies are needed to examine the I accumulation ability of a number of other leafy and tuber vegetable crops, in order to identify more efficient plant species as target crops for I supplementation and for particular population groups, taking into consideration their dietary patterns. Experiments are also needed to understand the bioavailability of I added to different types of soils and the quantitative relationship between soil I and I accumulated in plants. Investigations on I dynamics in soil-plant systems should also include selenium, as it has been reported that selenium concentration in the environment may also contribute to the prevalence of goiter (Fordyce et al., 2000). These studies are essential to ensure that soil- and crop-specific I rates are recommended for practical application.

\section{Acknowledgements}

This project was supported by the "Recruiting Outstanding Overseas Chinese Scientists" scheme of the Chinese Academy of Sciences, China. 


\section{References}

Borst Pauwels GWFH. Iodine as a micronutrient for plants. Plant Soil 1961; $14: 665-71$.

Böszörményi Z, Cseh E. The uptake and reduction of iodate by wheat roots. Curr Sci 1960;29:340-1.

Cao XY, Jiang XM, Kareem A, Dou ZH, Rakeman MA, Zhang ML, et al. Iodination of irrigation waters as a method of supplying iodine to a severely iodine-deficient population in Xinjiang, China. Lancet 1994; 344:107-9.

Fordyce FM, Johnson CC, Navaratna URB, Appleton JD, Dissanayake CB. Selenium and iodine in soil, rice and drinking water in relation to endemic goitre in Sri Lanka. Sci Total Environ 2000;263:127-41.

Herrett RA, Hatfield Jr HH, Crosby DG, Vlitos AJ. Leaf abscission induced by the iodine ion. Plant Physiol 1962;37:358-63.

Jiang XM, Cao XY, Jiang JY, Ma T, James DW, Rakeman MA, et al. Fouryear experience in iodination of irrigation water in Hotien, Xinjiang province of China. Arch Environ Health 1997;52:399-408.

Mackowiak CL, Grossl PR. Iodate and iodide effect on iodine uptake and partitioning in rice (Oryza sativa L.) grown in solution culture. Plant Soil 1999;212:135-43.

Muramatsu Y, Uchida S, Sumiya M, Ohmomo Y, Obata H. Tracer experiments on transfer of radio-iodine in the soil-rice plant system. Water Air Soil Pollut 1989;45:157-71.
Shinonaga T, Casta J, Muck K, Gerzabek MH. Determination of iodine in cereal grains and standard reference materials by neutron activation analysis. Int J Environ Anal Chem 2000;78:175-84.

Shinonaga T, Gerzabek MH, Strebl F, Muramatsu Y. Transfer of iodine from soil to cereal grains in agricultural areas of Austria. Sci Total Environ 2001;267:33-40.

Welch RM, Graham RD. A new paradigm for world agriculture: meeting human needs - productive, sustainable, nutritious. Field Crops Res 1999;60:1-10.

Whitehead DC. Uptake by perennial ryegrass of iodide, elemental iodine, and iodate added to soil as influenced by various amendments. J Sci Food Agric 1975;26:361-7.

World Bank. The challenge of dietary deficiencies of vitamins and minerals. Anonymous enriching lives: overcoming vitamin and mineral malnutrition in developing countries. Washington, DC: World Bank; 1994. p. $6-13$.

Xinjiang Disease Control Centre (XJDCC). Survey report of iodine deficiency disorders in Xinjiang Province, China in 1999. Endem Dis Bull 2000;15:59-63.

Zhang L, Chen Z, Wang J, Bao J. Iodine loss from iodinised salt during processing, sale and consumption. Zhejiang Prev Med 2000;12(6): $32-4$. 